\title{
Disease and Diagnosis
}

\section{Switching of Hashimoto Thyroiditis Into Graves' Disease: A Case Report and Literature Review}

\author{
Rajab Maksoud $^{1}$, Nour Maksoud ${ }^{1}{ }^{\circledR}$, Lubana Wannous ${ }^{1}{ }^{\circledR}$, Samaher Almousa $^{2 *(\mathbb{D}}$ \\ ${ }^{1}$ Endocrinology Department, Tishreen Hospital, Damascus, Syria. \\ ${ }^{2}$ Rheumatology and Immunology Department, Tishreen Hospital, Damascus, Syria.
}

\begin{abstract}
Background: Hashimoto thyroiditis (HT) and Graves' disease (GD) are autoimmune inflammatory thyroid disorders. The evolution from GD into HT is the most common scenario while the conversion from HT into GD seems to be less common.

Case Presentation: A 20-year-old female patient referred to the endocrinology clinic with a threemonth history of fatigue, lethargy, lack of appetite, constipation, menorrhagia, cold intolerance, and $5 \mathrm{~kg}$ weight gain in the last two months. Clinical examination showed dry skin, scalp hair loss, and painless hard goiter whereas thyroid ultrasound revealed generalized homogeneous hypoechoic thyroid hypertrophy. Laboratory tests demonstrated increased serum thyroid-stimulating hormone (TSH) $210 \mu \mathrm{IU} / \mathrm{L}$ (normal: 0.25-4.50), decreased free thyroxine (FT4) $0.37 \mathrm{ng} / \mathrm{L}$ (normal: 0.8-1.8) and free triiodothyronine (FT3) $1.94 \mathrm{pg} / \mathrm{mL}$ (normal: 1.8-4.6), and finally, increased thyroid peroxidase antibodies (anti-TPO) $462 \mathrm{IU} / \mathrm{mL}$ (normal: up to 34). Based on observations, HT was diagnosed and thus daily treatment with levothyroxine $75 \mathrm{mcg}$ was started for the patient. Two months later, she referred with symptoms suggestive of hyperthyroidism with reduced TSH levels, which did not improve after levothyroxine cessation, thus more laboratory tests were conducted and revealed decreased TSH levels, increased T3 and T4, and TSH receptor stimulating antibody (TSAb)levels, and increased radioactive iodine uptake at 24 hours. Therefore, the diagnosis of GD was made. Five weeks after treatment, she was in full remission.

Conclusion: Although the switch from HT into GD is rare, it can occur at any time during the disease. Nonetheless, early diagnosis and treatment would improve the quality of care.

Keywords: Hashimoto Thyroiditis, Graves disease, Autoimmune diseases
\end{abstract}

\author{
*Correspondence to \\ Samaher Almousa, \\ Rheumatology and \\ Immunology Department, \\ Tishreen Hospital, \\ Damascus, Syria. \\ Tel: +9635160050 \\ Email: samaher. \\ almousa123@gmail.com
}

Received: April 20, 2021, Accepted: May 3, 2021, ePublished: June 28, 2021

\section{Introduction}

Hashimoto thyroiditis (HT) is a chronic autoimmune inflammatory disease of thyroid glands (1) and causes hypothyroidism with a prevalence of approximately $0.8 \%$ of the population (2). However, Graves' disease (GD) is an autoimmune thyroid disorder that causes hyperthyroidism due to stimulating autoantibodies against thyroid-stimulating hormone (TSH) receptors localized on the membranes of the thyroid cells of the thyroid follicles (3). Women are affected more likely than men (4). The diagnosis of HT and GD depends on the presence of suggestive clinical manifestation with confirmed laboratory and radiological findings (5).

The relationship between these two diseases has been debated for decades. Although they were initially considered to be two separate diseases, the present view suggests that they represent the opposite sides of the same coin, or the two ends of the autoimmune spectrum (6). The evolution from GD into HT is the most common scenario
(7). Approximately $15 \%-20 \%$ of patients with GD have been reported to develop HT (7) while the conversion from HT into GD seems to be less common (8). The exact incidence of this conversion is unknown due to its rarity (8). On the other hand, autoimmune thyroid disorders could be associated with other autoimmune diseases such as vitiligo, Schmidt's disease, pernicious anemia, autoimmune adrenal insufficiency, diabetes mellitus type 1, systemic sclerosis, Sjögren syndrome, myasthenia gravis, systemic lupus erythematosus, and rheumatoid arthritis (9). This study reports a case of HT in a young Syrian female that had converted into GD.

\section{Case Presentation}

A 20-year-old Syrian female patient referred to the endocrinology clinic in Tishreen Hospital in Damascus with a three-month history of fatigue, lethargy, lack of appetite, constipation, menstrual disorder (menorrhagia), cold intolerance, and $5 \mathrm{Kg}$ weight gain in

(C) 2021 The Author(s). This is an open access article distributed under the terms of the Creative Commons Attribution License (http:// creativecommons.org/licenses/by/4.0/), which permits unrestricted use, distribution, and reproduction in any medium, provided the original work is properly cited. 
the last two months. Clinical examination demonstrated dry skin, scalp hair loss, normal pulse (60/minutes), and painless hard goiter while thyroid ultrasound represented generalized homogeneous hypoechoic thyroid hypertrophy. Laboratory tests were conducted and revealed increased serum TSH $210 \mu \mathrm{IU} / \mathrm{L}$ (normal: $0.25-4.50$ ), decreased free thyroxine (FT4) $0.37 \mathrm{ng} / \mathrm{L}$ (normal: 0.8-1.8), deceased free triiodothyronine (FT3) $1.94 \mathrm{pg} / \mathrm{mL}$ (normal: 1.8-4.6), and increased thyroid peroxidase antibodies (anti-TPO) $462 \mathrm{IU} / \mathrm{mL}$ (normal: up to 34). These findings were consistent with those of HT. Before the start of levothyroxine replacement therapy, a basal morning serum cortisol was performed to exclude Schmidt's syndrome, and the result was normal $21 \mu \mathrm{g} / \mathrm{dL}$ (normal: 5-25). The patient received daily treatment with levothyroxine 75 micrograms.

Six weeks later, clinical and laboratory improvements were observed except for the serum TSH level, which was $0.38 \mu \mathrm{IU} / \mathrm{L}$, suggesting levothyroxine overdose, consequently, the dose of levothyroxine was reduced to $50 \mu \mathrm{g} /$ daily and the patient was informed to refer to the endocrinology clinic after 6 weeks for the follow-up.

The patient was presented to the clinic with fatigue, insomnia, nervousness, palpitation, and mild weight loss without tremor or hyperhidrosis six weeks later. Clinical examinations demonstrated tachycardia (120/minutes), homogenous thyroid hypertrophy, mild muscular weakness, and stare without exophthalmos. Laboratory findings revealed reduced serum TSH levels of $0.1 \mu \mathrm{IU} / \mathrm{L}$ so that the suspicion of drug-induced hyperthyroidism was more likely to interpret these clinical and laboratory findings, thus levothyroxine was discontinued at this stage. In the follow-up period, our patient indicated no improvement regarding her clinical complaints, and she developed heat intolerance, excessive sweating, and overt weight loss of about $6 \mathrm{~kg}$. On clinical examination, there was thyroid bruit and painless soft diffuse goiter. Based on her laboratory findings, TSH, FT4, FT3, erythrocyte sedimentation rate (ESR), and TSH receptor stimulating antibodies (TSAb) were $0.001 \mu \mathrm{IU} / \mathrm{L}, 3.26 \mathrm{ng} / \mathrm{dL}, 12.45$ $\mathrm{pg} / \mathrm{mL}, 15 \mathrm{~mm} / \mathrm{h}$ (Re: 1-20), and $2.5 \mathrm{U} / \mathrm{L}$ (normal: up to 1.25), respectively. Radioactive iodine uptake represented diffusely increased uptake at 24 hours (Figure 1). Therefore, GD was diagnosed and $20 \mathrm{mg}$ of daily methimazole was introduced immediately.

Follow-up: After 5 weeks, our patient was symptomfree with the normalization of the serum TSH level $(2.2$ $\mu \mathrm{IU} / \mathrm{L})$, serum FT4 (1.2 ng/dL), anti-TPO (15 U/mL), and $\mathrm{TSAb}(1.1 \mathrm{U} / \mathrm{L})$. Indeed, the patient was in full remission.

\section{Discussion}

The occurrence of GD after HT is rare and the period of conversion ranges from months to years. The current study reported a case of hypothyroidism, which converted to hyperthyroidism within three months.

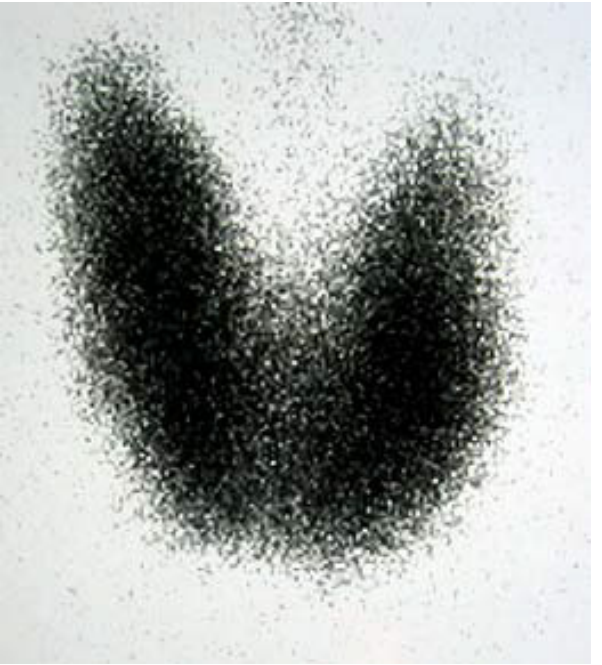

Figure 1. Radioactive lodine Uptake Revealing Diffusely Increased Uptake.

Our patient was diagnosed with HT, and thus she achieved euthyroidism after six weeks of treatment with levothyroxine, but this status was interrupted eight weeks later, when she developed symptoms suggesting hyperthyroidism that was confirmed with laboratory and radiological findings, implying the diagnosis of GD. The treatment with methimazole achieved full remission, and the patient was returned to euthyroid status. The overlap of autoimmune thyroid dysfunction with other autoimmune diseases is not unlikely, and several studies have mentioned this correlation such as diabetes mellitus, Addison's disease, systemic lupus erythematosus, rheumatoid arthritis, celiac disease, and the like $(9,10)$, and all these autoimmune diseases were excluded in our patient.

On the other hand, the progression of the thyroid immune diseases is similar to a pendulum clock dance, where they can develop from one form to another in the same patient and in both directions (11). HT and GD are the two main forms of a spectrum of thyroid immunological diseases (12). Although the conversion of $\mathrm{HT}$ to GD is a rare phenomenon and its mechanism is still unclear, a few cases were reported in the medical literature. Table 1 provides a summary of some cases (2,4,12-17).

The median period of this conversion is about $12-36$ months. In some cases, it was reported within decades, and most of the reported cases were middle-aged females (13).

It is still not well understood why a patient with established hypothyroidism later experiences hyperthyroidism. The most important hypothesized mechanism is the presence of different autoantibodies that includes thyroid blocking antibodies, thyroid-stimulating antibodies, and the response of the thyroid gland to these antibodies (13). Nonetheless, despite the inflammation and thyroid cell 
Table 1. Case Reports of the Conversion of Hashimoto Thyroiditis into Graves' Disease and the Present Case

\begin{tabular}{|c|c|c|c|c|c|}
\hline Case Report & Gender & Age (y) & Duration of Conversion (y) & Number of Cases & Year \\
\hline \multirow{2}{*}{ Kafrouni et al (13) } & \multirow{2}{*}{$\mathrm{F}$} & 41 & 18 & \multirow{2}{*}{2} & \multirow{2}{*}{2019} \\
\hline & & 62 & 16 & & \\
\hline Ekpebegh et al (15) & $\mathrm{F}$ & 54 & 5 & 1 & 2019 \\
\hline Gonzalez-Aguilera et al (16) & $\mathrm{F}$ & $33-55$ & $1-3$ & 24 & 2018 \\
\hline Brondfield et al (4) & M & 26 & 12 & 1 & 2016 \\
\hline \multirow[t]{2}{*}{ Pak et al (12) } & $\mathrm{F}$ & 12 & $\mathrm{~N} / \mathrm{A}$ & 1 & 2017 \\
\hline & $\mathrm{F}$ & 36 & 1 & & \\
\hline \multirow[t]{2}{*}{ Furqan et al (17) } & $\mathrm{F}$ & 46 & 1 & 3 & 2014 \\
\hline & $\mathrm{F}$ & 43 & 9 months & & \\
\hline The present case & $\mathrm{F}$ & 25 & 3 months & 1 & 2020 \\
\hline
\end{tabular}

destruction because of the lymphocytic infiltration of the thyroid gland in chronic autoimmune thyroiditis (HT), there are still small numbers of functioning cells which are sufficient to respond to the stimulatory effect of TSAb in GD (17).

Moreover, many possible causes have been proposed to be responsible for the immune conversion (from TSBAb to TSAb and vice versa), including levothyroxine or anti-thyroid drug replacement therapy, immunological shifts occurring during pregnancy, and environmental and infectious factors in genetically susceptible people. Emotional and physical stress are also suggested as possible causes (8). The clinical manifestation is determined by the antibody which predominates. This can vary with time in the same patient and clinically manifests as HT or GD (17). The pathogenesis of switching GD to HD is unclear. Hashimoto disease occurs due to prolonged immune response, which includes the response to endogenous thyroid antigens (i.e., thyroglobulin and thyroid peroxidase). It enhances the infiltration of lymphocytes into the thyroid glands leading to HD (7).

It is hoped that the present report raises awareness about this rare phenomenon among clinicians and describes the potential mechanisms behind such a change. Further, improvements in identifying and recognizing this conversion process between GD and HT would allow clinicians to early implement appropriate treatment, thus increasing the quality of care.

\section{Conclusion}

Although the switch from HT into GD is rare, it should be noted that it can occur at any time during the disease (13). Therefore, the authors recommend that hyperthyroidism should be considered in any patient with controlled hypothyroidism presenting with clinical and biochemical findings indicating hyperthyroidism that persists even after stopping levothyroxine.

\section{Conflict of Interest Disclosures}

The authors declare that they have no conflict of interests.

\section{Acknowledgements}

None.

\section{Ethical Statement}

This study was approved by the Ethics Committee of Medical Service Administration.

\section{Authors' Contribution}

RM: Diagnosis of the case and supervision. NM: Collecting data and clinical story. LW and SA: Writing and editing the case.

\section{Funding/Support}

This research received no specific grant from funding agencies in the public, commercial, or not-for-profit sectors.

\section{Informed Consent}

The patient signed the informed consent for participation in the study.

\section{References}

1. Swain M, Swain T, Mohanty BK. Autoimmune thyroid disorders-an update. Indian J Clin Biochem. 2005;20(1):917. doi: $10.1007 / \mathrm{bf0} 2893034$.

2. Wahedi TS, Douba NY. SAT-497 conversion of Hashimoto's thyroiditis to Grave's disease: a case report. J Endocr Soc. 2020;4(Suppl 1):SAT-497. doi: 10.1210/jendso/ bvaa046.1447.

3. Antonelli A, Ferrari SM, Corrado A, Di Domenicantonio A, Fallahi P. Autoimmune thyroid disorders. Autoimmun Rev. 2015;14(2):174-80. doi: 10.1016/j.autrev.2014.10.016.

4. Brondfield S, Feingold KR. Symptomatic Graves' disease after autoimmune hypothyroidism. Am J Med. 2016;129(5):e19-20. doi: 10.1016/j.amjmed.2015.12.017.

5. Demers LM, Spencer CA. Laboratory medicine practice guidelines: laboratory support for the diagnosis and monitoring of thyroid disease. Clin Endocrinol (Oxf). 2003;58(2):138-40. doi: 10.1046/j.1365-2265.2003.01681.x.

6. Gola M, Doga M, Mazziotti G, Bonadonna S, Giustina A. Development of Graves' hyperthyroidism during the early phase of pregnancy in a patient with pre-existing and longstanding Hashimoto's hypothyroidism. J Endocrinol Invest. 2006;29(3):288-90. doi: 10.1007/bf03345556.

7. Umar H, Muallima N, Adam JM, Sanusi H. Hashimoto's 
thyroiditis following Graves' disease. Acta Med Indones. 2010;42(1):31-5.

8. Bravo-Llerena WE, Valderrabano-Wagner RJ, QuevedoQuevedo J, Reyes-Ortiz LM. Development of Grave's disease seven months after Hashimoto's thyroiditis: a rare occurrence. Bol Asoc Med P R. 2010;102(3):76-8.

9. Almousa S, Ahmad T, Hamdan S, Katt N. Lupus erythematosus tumidus (LET) with autoimmune thyroid dysfunction (AITD) as the first presentation of systemic lupus erythematosus: a case report and review of the literature. Egypt Rheumatol. 2020;42(3):245-50. doi: 10.1016/j.ejr.2020.02.002.

10. Fallahi P, Ferrari SM, Ruffilli I, Elia G, Biricotti M, Vita R, et al. The association of other autoimmune diseases in patients with autoimmune thyroiditis: review of the literature and report of a large series of patients. Autoimmun Rev. 2016;15(12):1125-8. doi: 10.1016/j.autrev.2016.09.009.

11. Champion B, Gopinath B, Ma G, El-Kaissi S, Wall JR. Conversion to Graves' hyperthyroidism in a patient with hypothyroidism due to Hashimoto's thyroiditis documented by real-time thyroid ultrasonography. Thyroid. 2008;18(10):1135-7. doi: 10.1089/thy.2008.0142.

12. Pak S, Valencia D, Fershko A. Transformation of
Hashimoto's thyroiditis to Graves' disease. Res Rev Insights. 2017;1(3):1-2. doi: 10.15761/rri.1000117.

13. Kafrouni Gerges AR, Clark SN, Shawa H. Hypothyroidism to hyperthyroidism: an immunological pendulum swing from two extreme poles - a case series. BMJ Case Rep. 2019;12(4):e227445. doi: 10.1136/bcr-2018-227445.

14. McLachlan SM, Nagayama Y, Pichurin PN, Mizutori Y, Chen CR, Misharin A, et al. The link between Graves' disease and Hashimoto's thyroiditis: a role for regulatory T cells. Endocrinology. 2007;148(12):5724-33. doi: 10.1210/ en.2007-1024.

15. Ekpebegh C, Elmezughi K, Mtingi L. Graves' disease following hypothyroidism due to Hashimoto's thyroiditis in a black South African lady: a case report. Pan Afr Med J. 2019;32:186. doi: 10.11604/pamj.2019.32.186.18713.

16. Gonzalez-Aguilera B, Betea D, Lutteri L, Cavalier E, Geenen V, Beckers A, et al. Conversion to Graves disease from Hashimoto thyroiditis: a study of 24 patients. Arch Endocrinol Metab. 2018;62(6):609-14. doi: 10.20945/23593997000000086.

17. Furqan S, Haque NU, Islam N. Conversion of autoimmune hypothyroidism to hyperthyroidism. BMC Res Notes. 2014;7:489. doi: 10.1186/1756-0500-7-489. 